\title{
Increase of aggregative and sedimentation stability of slag suspensions by ultrasound
}

\author{
Svetlana Samchenko ${ }^{1}$, Irina Kozlova ${ }^{1,{ }^{*}}$, Olga Zemskova $^{1}$ and Ekaterina Baskakova ${ }^{1}$ \\ ${ }^{1}$ Moscow State University of Civil Engineering, Yaroslavskoye shosse, 26, Moscow, 129337, Russia
}

\begin{abstract}
The paper discusses the relevance of the use of metallurgical wastes crushed to a fine state in the production of building materials. Domain granulated slag (DGS) was used as a research object. A method for introducing fine ground slag (FGS) into the cement composition in the form of a slag suspension instead of mixing water has been developed. To establish the uniform distribution of FGS particles in the cement matrix, the behavior of slag particles in an aqueous dispersion medium was previously studied. The optimal parameters of ultrasonic dispersion of slag suspensions are established: the frequency of ultrasonic vibrations is 44 $\mathrm{kHz}$; temperature of dispersion $-25 \pm 2^{\circ} \mathrm{C}$; dispersion time - $15 \mathrm{~min}$. It has been established that the application of UST to slag suspensions with the observance of optimal dispersion parameters can increase the aggregative and sedimentation stability of the FGS suspension by 2-3 times as compared with mechanical mixing, accelerate the micelle formation process, and enhance the electrostatic factor of aggregative stability.
\end{abstract}

\section{Introduction}

The ecological situation in our country and all over the world requires paying attention to the recycling of large-tonnage industrial waste. One of the ways of recycling is the use of waste as a secondary raw material in the construction industry [1-7]. In the cement industry, the waste of metallurgical production - granulated blast-furnace slag (GBFS) [8-9] is used as a raw material component and active mineral additive. It is known that products made of slag-based cements have a number of advantages over the plain Portland cement. These include: low exothermic reaction, increased corrosion and heat resistance, workability of concrete mix, protection of finished structures from weathering and cracking, - which generally increases the durability of structures [10-13]. Due to the slow set of strength at the initial time of hardening, this kind of cement was not widely used in civil engineering. To solve this problem, it was proposed to use hardening accelerators, complex additives, and superplasticizers in slag cements [14-17]. In work [17], electrolytes, in particular, the system of additives "Relaxol-Leader" based on the technogenic mixture of sodium thiocyanate and thiosulfate, which allows increasing the strength of slag Portland cement by $50-88 \%$, were used as accelerators for hardening of slag Portland cement (SPC).

The authors of works [18-19] considered the preparation of cements and cement compositions with finely ground steel-smelting slags that, during combined hydration with

\footnotetext{
*Corresponding author: iv.kozlova@mail.ru
} 
cement, form hydration products in the form of submicrocrystalline hydrate phases that compact the structure of the cement stone and further bind the individual grains of the composition, which leads to the hardening of its structure.

Due to the fact that the scales of formation of blast-furnace slags are twice as high as the formation of steel-smelting slags, the present paper considers the use of GBFS as a finely dispersed component involved in the structure formation of the cement matrix.

The use of finely dispersed particles, including GBFS, in cement is accompanied with a number of problems, which include:

- difficulty of introducing them into the cement;

- uneven distribution in the volume of the binder;

- instability of the results of physical and mechanical tests of cement stone.

To solve these problems, studies were carried out to determine the optimal conditions for the introduction and distribution of finely ground GBFS (FGS) in the volume of the cement matrix, which contributes to the obtaining of stable characteristics of the cement stone.

\section{Experimental}

In this work, a granulated blast-furnace slag subjected to grinding in a laboratory jet mill LHL-1 with a limitation of the upper grinding boundaries to a size of 1 micron was used as an object of study. The characteristics of the granulated blast-furnace slag, including chemical and phase compositions, the slag quality factor, and the basicity factor, are given in Table 1. The granulometric composition of finely ground slag (FGS) is presented in Table. 2.

Table 1. Characteristics of granulated blast-furnace slag.

\begin{tabular}{|c|c|c|c|c|c|c|c|c|c|}
\hline \multicolumn{6}{|c|}{ Chemical composition of slag, $\%$} & \multicolumn{2}{|c|}{$\begin{array}{c}\text { Phase composition } \\
\text { of slag, } \%\end{array}$} & \multirow{2}{*}{$\begin{array}{c}\text { Slag } \\
\text { quality } \\
\text { factor Fq }\end{array}$} & \multirow{2}{*}{$\begin{array}{c}\text { Basicity } \\
\text { factor } \\
\mathrm{Fb}\end{array}$} \\
\hline $\mathrm{CaO}$ & $\mathrm{SiO}_{2}$ & $\mathrm{Al}_{2} \mathrm{O}_{3}$ & $\mathrm{MgO}$ & $\begin{array}{c}\mathrm{Fe}_{2} \mathrm{O}_{3}+ \\
\mathrm{FeO}\end{array}$ & Other & Glass & $\begin{array}{l}\text { Crystalline } \\
\text { phase }\end{array}$ & & \\
\hline 45.40 & 38.20 & 8.10 & 3.20 & 0.80 & 4.30 & 93.20 & 6.80 & 1.45 & 1.1 \\
\hline
\end{tabular}

Table 2. Granulometric composition of FGS.

\begin{tabular}{|l|c|c|c|c|c|c|c|}
\hline Particle size, micron & $0-0.5$ & $0.5-1.0$ & $1.0-1.5$ & $1.5-2.0$ & $2.0-3.0$ & $3.0-4.0$ & $4.0-5.0$ \\
\hline $\begin{array}{l}\text { Fraction content, } \\
\text { mass.\% }\end{array}$ & 8.21 & 30.44 & 23.35 & 17.20 & 11.77 & 5.89 & 3.14 \\
\hline
\end{tabular}

It follows from Table 1 that the slag basicity factor $\mathrm{Fb}=1.1$; Oxides of $\mathrm{CaO}$ and $\mathrm{SiO}_{2}$ predominate in the FGS. For which reason the presence of basic calcium orthosilicates, mainly $\mathrm{Ca}_{2} \mathrm{SiO}_{4}$, is expected in FGS.

It follows from Table 2 that the FGS obtained in a laboratory jet mill has a predominant particle size of $0.5-1.0$ micron. Such a size of FGS allows it to be attributed to submicron particles, which, like nanoparticles, tend to aggregate. The introduction of FGS into the cement composition as a dry powder does not allow obtaining stable results of physical and mechanical tests. For that reason slag suspensions based on FGS were obtained, and studies were conducted to establish the aggregative and sedimentation stability of suspensions in an aqueous dispersion medium [20]. It is established that the sedimentation process of FGS is divided into 3 periods, and the particles precipitate most rapidly in the first sedimentation period. Our earlier studies on the dispersion and homogenization of carbon nanotubes (CNTs) in a water-polymer dispersion medium by the method of acoustic cavitation (ultrasonic dispersion) made it possible to obtain CNT suspensions capable of evenly 
distribution in the volume of the cement matrix [21-24]. It is assumed that the ultrasonic treatment (UST) of the slag particles will lead to the destruction of larger particles and a decrease in the rate of their precipitation in the first sedimentation period.

Dispersing of FGS was carried out on the device UZDN-I. To effectively separate FGS in suspension, studies were carried out to optimize the dispersion parameters: ultrasonic vibration frequency $(v)$, dispersion time $(\tau)$, and dispersion temperature. The definition of each optimal parameter passed with the constancy of the others. In studies on optimization of the dispersion conditions, a suspension of FGS with a concentration of $50 \mathrm{~g} / \mathrm{l}(5 \%)$ was used. The indicator of the dispersion quality of FGS was the compression strength of diurnal samples in the size of $20 \times 20 \times 20 \mathrm{~mm}$, mixed with the same suspension with different dispersion parameters, i.e.

$$
\operatorname{Rc}_{(\text {day })}=f(\tau, \mathrm{t})
$$

Determination of the optimal time of ultrasonic treatment of FGS suspension was carried out by establishing the dependence $\mathrm{Rc}_{(\text {day) }}=f(\tau)$, where $\tau=10,20,30,40,50,60$ minutes. The parameters $\mathrm{t}=$ const, $v=$ const. The obtained dependence is shown in Fig. 1a. It was found that for $\tau \geq 15 \mathrm{~min}$, the compression strength is constant, and the optimal dispersion time of FGS suspension (concentration $50 \mathrm{~g} / \mathrm{l}$ ) is 15 minutes.

The effectiveness of the dispersion of FGS depends on the temperature control of the dispersion process. Determination of the dispersion temperature was carried out by establishing the dependence $\mathrm{Rc}{ }_{\text {(day) }}=f(\mathrm{t})$, where $\mathrm{t}=17,20,25,30,40,50{ }^{\circ} \mathrm{C}$. The parameters $\tau=$ const, $v=$ const. The obtained dependence is shown in Fig. $1 \mathrm{~b}$. It was found that a decrease in compression strength was observed in diurnal samples at $t_{\mathrm{dm}} \geq 35^{\circ} \mathrm{C}$. At high temperatures, two competing processes occur simultaneously: diffusion transfer of particles (Brownian motion of particles) leading to an increase in the uniformity of the disperse system and coagulation, which causes the consolidation of particles' aggregates. In the system, there is a violation of the balance of processes, which leads to a decrease in the efficiency of particle dispersion. Thus, it is recommended to carry out temperature control of the dispersion process of FGS at a temperature of $25 \pm 2{ }^{\circ} \mathrm{C}$.

a.

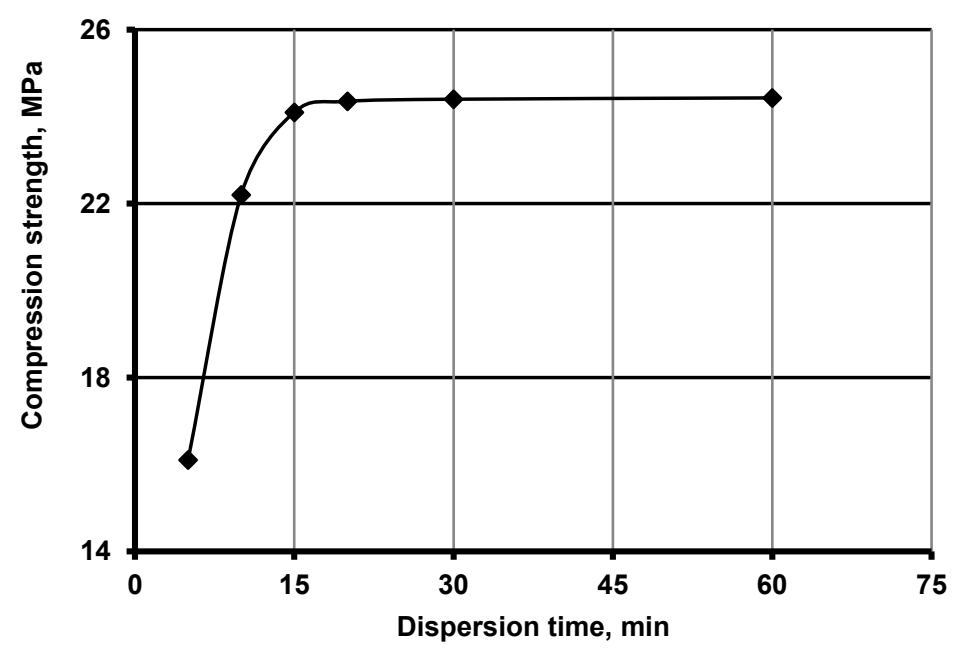


b.

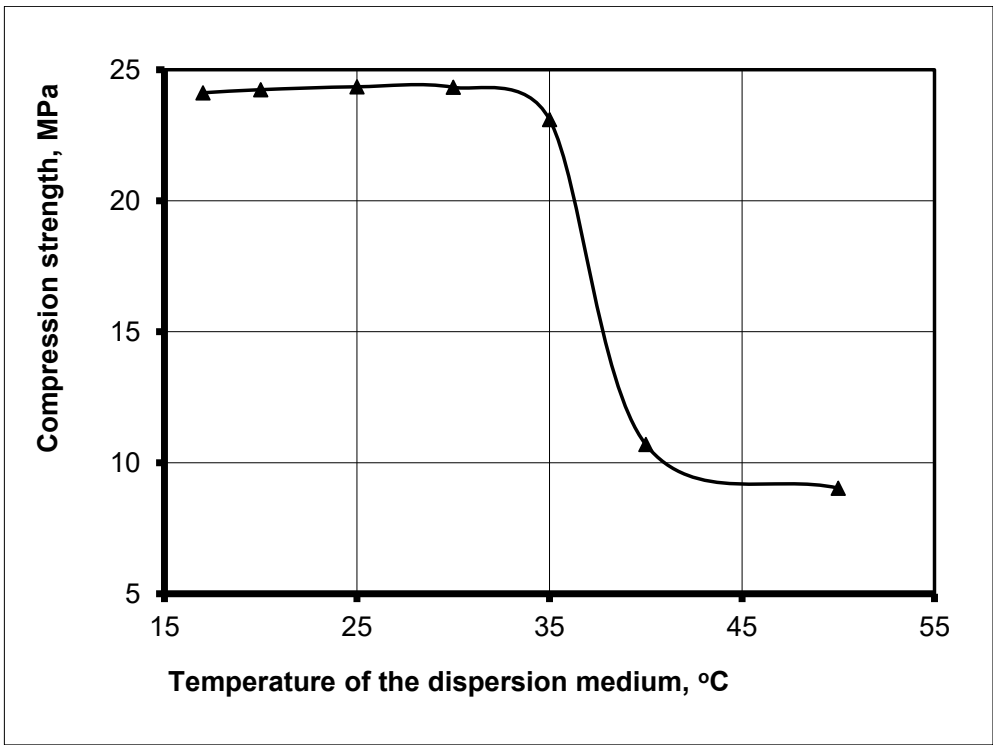

Fig. 1. Selection of dispersion parameters for suspensions of FGS: a) $\operatorname{Rc}_{(\text {day })}=f(\tau)$; b) $\operatorname{Rc}_{(\text {day })}=f(\mathrm{t})$.

The frequency of ultrasonic dispersion is constant and equal to $44 \mathrm{kHz}$.

Therefore, the dispersion and homogenization of FGS in the suspension should be carried out for 15 minutes with a frequency of ultrasonic vibrations of $44 \mathrm{kHz}$ and a dispersion temperature of $25 \pm 2^{\circ} \mathrm{C}$.

The established dependences $\mathrm{Rc}_{\text {(day) }}=f(\tau, \mathrm{t})$ are coherent with the curves of distribution of FGS (Fig.2) obtained on the Mastersizer 3000 (UK), which confirms the possibility of using the indirect method proposed by us in assessing the uniformity of FGS distribution both in suspension and in the volume of the cement matrix.

a. q, \%

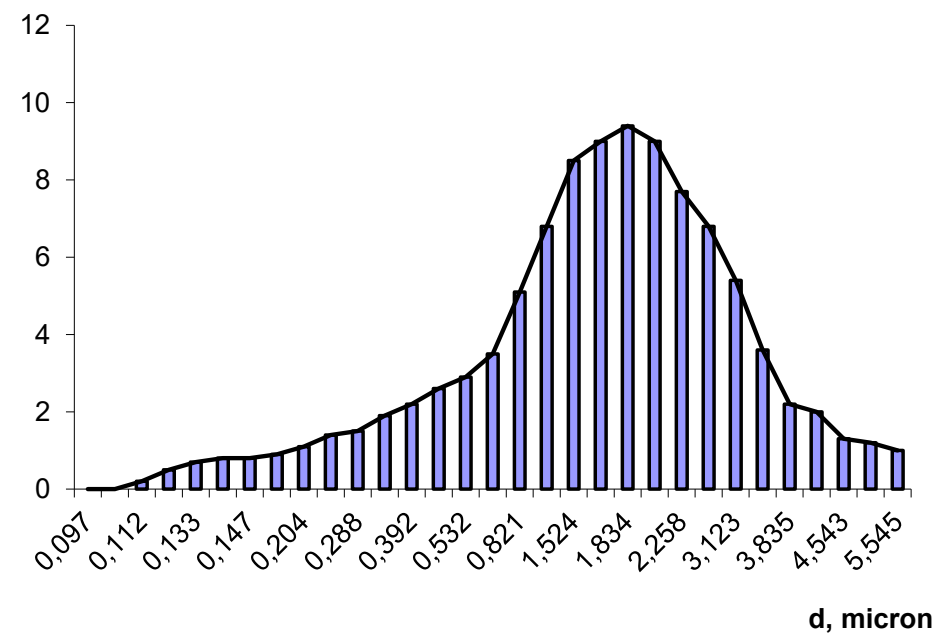


b. $\quad$ q, $\%$

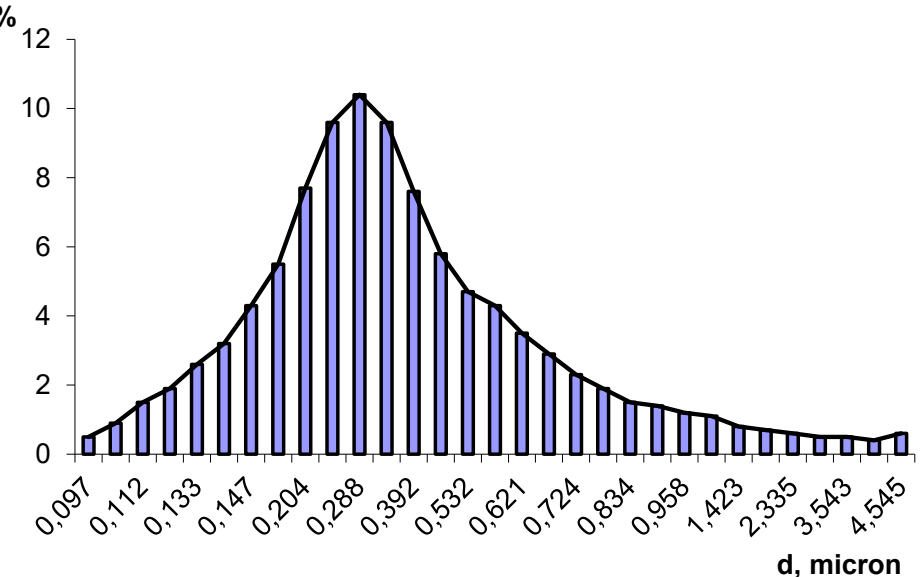

Fig. 2. The distribution curves of FGS particles in the suspension after UST: a) at $\mathrm{t}=25^{\circ} \mathrm{C} ; \tau=15$ $\min ; \mathrm{b})$ at $\mathrm{t}=50^{\circ} \mathrm{C} ; \tau=15 \mathrm{~min}$.

From the graphs in Figure 2, it follows that carrying out ultrasonic dispersion in the absence of temperature control leads to a shift in the size of FGS particles towards the coarsening. This is explained by the fact that an increase in the dispersion temperature causes an accelerated flow of coagulation processes in FGS suspensions and leads to a regular increase in the kinetic energy that FGS acquires according to the following equation:

$$
E_{k}=\frac{d_{f}^{2} \cdot \rho_{f} \cdot k_{b} \cdot T}{36 \eta}
$$

where $d_{f}$ - particle diameter, $\mathrm{m} ; \rho_{f}$ - density, $\mathrm{kg} / \mathrm{m}^{3} ; k_{b}=1,38 \cdot 10^{-23} \mathrm{~J} / \mathrm{K}-$ Boltzmann's constant; $\mathrm{T}$ - temperature of the dispersion medium, $\mathrm{K} ; \eta$ - coefficient of dynamic viscosity of the medium, $\mathrm{Pa} \cdot \mathrm{s}$,

Therefore, the most significant parameter in assessing the quality of separation and homogenization of FGS particles in the suspension is the dispersion temperature. To maintain a constant dispersion temperature, it is necessary to carry out the dispersion of slag suspensions using a thermostat.

\section{Evaluation}

When FGS is introduced in an aqueous dispersion medium, hydrolysis and hydration processes begin to take place with the formation of calcium hydroxide and calcium hydrosilicates of different basicity [20]. In an aqueous dispersion medium, FGS particles are surrounded by water dipoles and adsorbed on the FGS surface (Fig. 3). The FGS particles acquire a negative charge of the surface. A double electric layer is formed on the interphase surfaces, which, together with the dispersed phase, forms FGS micelle (micelle 1) (Fig. 4). 

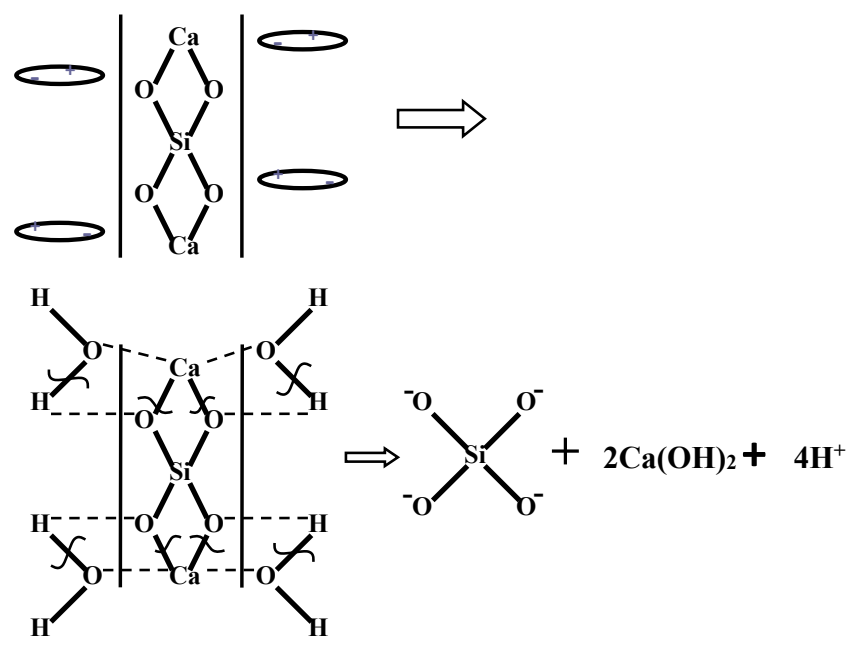

Fig. 3. The mechanism of interaction of FGS with water micelle structure (micelle 1).

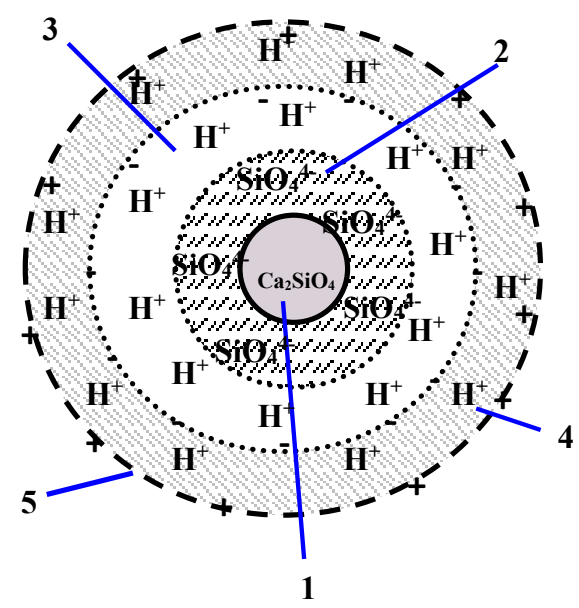

Fig. 4. Scheme of FGS: 1 - aggregate of FGS; 2 - layer of potential-determining ions; 3 - counter ions of a dense part of a double electric layer; 4 - counter ions of the diffuse layer; 5 - FGS micelle.

As the hydration reaction proceeds, reaction products are formed on the FGS surface and the solution becomes saturated with $\mathrm{Ca}^{2+}$ and $\mathrm{OH}^{-}$ions. The formed $\mathrm{Ca}^{2+}$ ions with a larger charge and size than the $\mathrm{H}^{+}$ion replace it in the diffusion and adsorption layers, penetrate to the surface of colloidal particles with active sites, causing the chemisorption process (Fig. 5). The $\mathrm{Ca}^{2+}$ ions, which are in excess, become potential-forming, the FGS surface is charged positively (FGS micelle - micelle 2) (Fig. 6). 


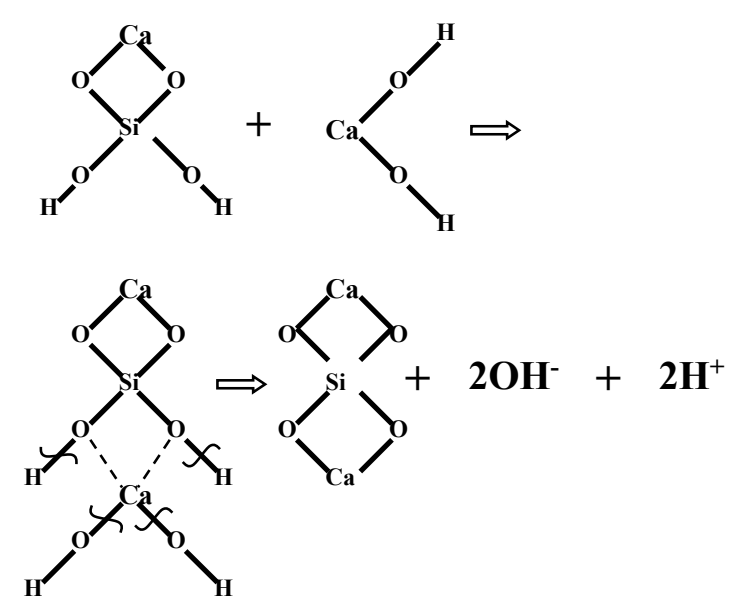

Fig. 5. The mechanism of the chemisorption process on the FGS surface.

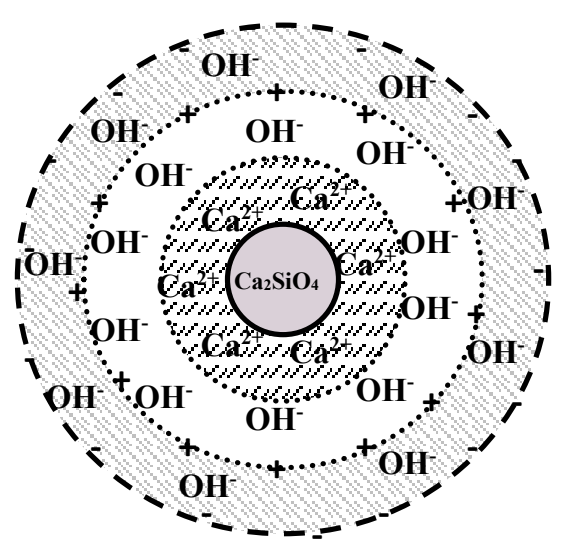

Fig. 6. Scheme of FGS micelle structure (micelle 2).

Thus, in the aqueous suspension of FGS, two types of micelles (micelle 1, micelle 2) are formed in which the slag particles are charged negatively and positively, respectively. The presence of a double electric layer in FGS particles due to the electrostatic stability factor causes the aggregate and sedimentation stability of the "FGS-water" system.

To increase the amount of FGS particles with a positive charge of surface, slag suspensions were exposed to ultrasonic dispersion. Suspensions with concentrations of 10 $\mathrm{g} / \mathrm{l}(1 \%) ; 30 \mathrm{~g} / 1(3 \%) ; 50 \mathrm{~g} / 1(5 \%)$ were used for the studies.

Table 3 shows the results of an experiment on the establishment of aggregative and sedimentation stability of FGS suspensions in an aqueous dispersion medium using ultrasonic dispersion at $v=44 \mathrm{kHz}, \tau=15 \mathrm{~min}$ and $\mathrm{t}_{\mathrm{dm}}=25^{\circ} \mathrm{C}$. Table 4 presents a 
comparative analysis of the sedimentation rates of FGS particles after UST and without UST.

Table 3. Time and rate of sedimentation of FGS particles in an aqueous dispersion medium.

\begin{tabular}{|c|c|c|c|c|c|c|c|c|}
\hline \multirow[b]{3}{*}{ № } & \multirow{3}{*}{$\begin{array}{c}\text { Experi } \\
\text { mental } \\
\text { conditi } \\
\text { ons }\end{array}$} & \multirow{3}{*}{$\begin{array}{c}\text { Concentrati } \\
\text { on of FGS, } \\
\mathrm{g} / \mathrm{l}(\%)\end{array}$} & \multicolumn{6}{|c|}{ Sedimentation period of particles } \\
\hline & & & \multicolumn{2}{|c|}{$\mathrm{I}$} & \multicolumn{2}{|c|}{ II } & \multicolumn{2}{|c|}{ III } \\
\hline & & & $\begin{array}{c}\text { Particle } \\
\text { sedimentati } \\
\text { on time, } \\
\text { min-s }\end{array}$ & $\begin{array}{c}\text { Particle } \\
\text { sedimentati } \\
\text { on rate, } 10^{-} \\
{ }^{5} \mathrm{~m} / \mathrm{s}\end{array}$ & $\begin{array}{c}\text { Particle } \\
\text { sedimentati } \\
\text { on time, } \\
\text { min-s }\end{array}$ & $\begin{array}{c}\text { Particle } \\
\text { sedimentati } \\
\text { on rate, } 10^{-} \\
5 \mathrm{~m} / \mathrm{s}\end{array}$ & $\begin{array}{c}\text { Particle } \\
\text { sedimentati } \\
\text { on time, h- } \\
\text { min }\end{array}$ & $\begin{array}{c}\text { Particle } \\
\text { sedimentati } \\
\text { on rate, } 10^{-} \\
{ }^{5} \mathrm{~m} / \mathrm{s}\end{array}$ \\
\hline 1 & \multirow{3}{*}{$\begin{array}{l}\text { Witho } \\
\text { ut } \\
\text { UST }\end{array}$} & $10(1)$ & $8-05$ & 30.20 & $30-00$ & 8.22 & $2-30$ & 1.64 \\
\hline 2 & & $30(3)$ & $6-20$ & 34.40 & $20-00$ & 11.00 & $2-25$ & 1.68 \\
\hline 3 & & $50(5)$ & $6-10$ & 39.50 & $16-00$ & 14.30 & $2-20$ & 1.72 \\
\hline 4 & \multirow{3}{*}{$\begin{array}{l}\text { After } \\
\text { UST }\end{array}$} & $10(1)$ & $20-00$ & 12.80 & $60-00$ & 4.33 & $5-30$ & 0.79 \\
\hline 5 & & $30(3)$ & $15-00$ & 13.80 & $34-00$ & 7.33 & $5-20$ & 0.81 \\
\hline 6 & & $50(5)$ & $13-00$ & 18.30 & $32-00$ & 7.61 & $5-00$ & 0.86 \\
\hline
\end{tabular}

Table 4. Comparative analysis of sedimentation rates of FGS particles in suspension after UST and without UST.

\begin{tabular}{|c|c|c|c|c|}
\hline \multirow{2}{*}{ № } & \multirow{2}{*}{ Concentration of FGS, g/1 (\%) } & \multicolumn{3}{|c|}{${\text { Vwithout UST } / \mathrm{V}_{\text {after UST }}}$} \\
\cline { 3 - 5 } & & I & II & III \\
\hline 1 & $10(1)$ & 2.35 & 1.90 & 2.08 \\
\hline 2 & $30(3)$ & 2.49 & 1.50 & 2.07 \\
\hline 3 & $50(5)$ & 2.16 & 1.88 & 2.00 \\
\hline
\end{tabular}

From the data given, it follows that when the slag suspension was under ultrasonication, the stability of FGS particles increased by an average of 2-3 times in comparison with slag suspensions which were not under ultrasonication.

Under the influence of ultrasonic vibrations, the slag particles are vigorously mixed in an aqueous dispersion medium and destroyed, forming FGS particles with a smaller size and a larger number of active surface centers than in the case of mechanical mixing. The slag particles after the UST also form micelles 1 and 2. The process of micelle formation with the participation of finely dispersed slags passes much faster after the UST than the same process in systems without the use of UST. Water-dispersed systems using UST behave more stable, the electrostatic factor of aggregative stability is enhanced.

To assess the effect of the prepared FGS suspensions after the UST under the recommended dispersion conditions and without the use of UST, a cement stone test was carried out on the basis of PC with the addition of a slag suspension. The results of the experiment are given in Table 5.

Table 5. Comparison of the strength characteristics of the samples with the slag suspension after the UST under the recommended dispersion conditions and without the use of UST.

\begin{tabular}{|c|c|c|c|c|c|c|}
\hline \multirow[b]{2}{*}{ № } & \multirow{2}{*}{$\begin{array}{c}\text { Conditions of suspension } \\
\text { preparation }\end{array}$} & \multirow{2}{*}{$\begin{array}{l}\text { Concentration } \\
\text { of FGS, } g / 1 \\
(\%)\end{array}$} & \multicolumn{4}{|c|}{ Compression strength of samples, MPa } \\
\hline & & & 1 day & 3 days & 7 days & 28 days \\
\hline 1 & - & - & 14.2 & 19.3 & 33.2 & 62.8 \\
\hline 2 & \multirow{3}{*}{ Mechanical mixing } & 10 & 16.2 & 27.9 & 38.9 & 69.6 \\
\hline 3 & & 30 & 17.9 & 31.9 & 42.8 & 75.9 \\
\hline 4 & & 50 & 15.8 & 28.9 & 44.1 & 79.6 \\
\hline 5 & UST $(v=44 \mathrm{kHz}, \tau=15$ & 10 & 18.3 & 29.6 & 40.9 & 74.8 \\
\hline
\end{tabular}




\begin{tabular}{|l|c|c|c|c|c|c|}
\hline 6 & min and & 30 & 19.8 & 34.9 & 48.6 & 80.2 \\
\cline { 3 - 7 } & $\left.\mathrm{t}_{\mathrm{dm}}=25^{\circ} \mathrm{C}\right)$ & 50 & 16.9 & 31.6 & 48.2 & 85.2 \\
\hline
\end{tabular}

From the results presented in Table 5, it follows that the strength characteristics of samples with FGS suspensions prepared using UST under the recommended dispersing conditions are higher than without the use of UST. For the first day of hardening, strength increased by $19-39 \%$; for 28 days of hardening - by $19-36 \%$. This confirms the effectiveness of the use of UST in the preparation of slag suspensions.

Also, studies were conducted to determine the influence of FGS suspensions prepared under dispersion conditions deviated from the recommended ones on the strength of samples. The results are summarized in Table 6.

Table 6. Strength characteristics of samples with a slag suspension using UST under dispersion conditions deviated from the recommended ones.

\begin{tabular}{|c|c|c|c|c|c|c|}
\hline \multirow[b]{2}{*}{ № } & \multirow{2}{*}{$\begin{array}{c}\text { Conditions of suspension } \\
\text { preparation }\end{array}$} & \multirow{2}{*}{$\begin{array}{c}\text { Concentration } \\
\text { of FGS, } g / 1 \\
(\%)\end{array}$} & \multicolumn{4}{|c|}{ Compression strength of samples, MPa } \\
\hline & & & 1 day & 3 days & 7 days & 28 days \\
\hline 1 & - & - & 14.2 & 19.3 & 33.2 & 62.8 \\
\hline 2 & \multirow{3}{*}{$\begin{array}{c}\text { UST }(v=44 \mathrm{kHz}, \tau=15 \\
\left.\text { min and } \mathrm{t}_{\mathrm{dm}}=40^{\circ} \mathrm{C}\right)\end{array}$} & $10(1)$ & 15.3 & 25.1 & 38.3 & 70.1 \\
\hline 3 & & $30(3)$ & 16.1 & 31.2 & 43.4 & 78.3 \\
\hline 4 & & $50(5)$ & 15.5 & 28.4 & 43.9 & 80.4 \\
\hline 5 & \multirow{3}{*}{$\begin{array}{c}\text { UST }(v=44 \mathrm{kHz}, \tau=15 \\
\left.\text { min and } \mathrm{t}_{\mathrm{dm}}=50^{\circ} \mathrm{C}\right)\end{array}$} & $10(1)$ & 12.4 & 22.3 & 34.6 & 67.4 \\
\hline 6 & & $30(3)$ & 13.3 & 26.6 & 39.5 & 68.3 \\
\hline 7 & & $50(5)$ & 13.9 & 24.1 & 37.6 & 76.7 \\
\hline
\end{tabular}

It follows from Table 6 that during the ultrasonic treatment of slag suspensions at $\mathrm{t}_{\mathrm{dm}}>40^{\circ} \mathrm{C}$, the strength characteristics of samples with the use of slag suspensions are significantly reduced. An increase in the dispersion temperature accelerates the thermal motion of the particles and deepens the coagulation of FGS, which is confirmed by the data given in Table 7 .

Table 7. Time and rate of sedimentation of FGS particles in an aqueous medium after the UST under dispersion conditions deviated from the recommended ones.

\begin{tabular}{|c|c|c|c|c|c|c|c|c|}
\hline \multirow[b]{3}{*}{ № } & \multirow{3}{*}{$\begin{array}{l}\text { Conditio } \\
\text { ns of } \\
\text { suspensi } \\
\text { on } \\
\text { preparati } \\
\text { on }\end{array}$} & \multirow{3}{*}{$\begin{array}{c}\text { Concentrati } \\
\text { on of FGS, } \\
\mathrm{g} / 1(\%)\end{array}$} & \multicolumn{6}{|c|}{ Sedimentation period of particles } \\
\hline & & & \multicolumn{2}{|c|}{$\mathrm{I}$} & \multicolumn{2}{|c|}{ II } & \multicolumn{2}{|c|}{ III } \\
\hline & & & $\begin{array}{c}\text { Particle } \\
\text { sedimentati } \\
\text { on time, } \\
\text { min-s }\end{array}$ & $\begin{array}{c}\text { Particle } \\
\text { sedimentati } \\
\text { on rate, } 10^{-} \\
{ }^{5} \mathrm{~m} / \mathrm{s}\end{array}$ & $\begin{array}{c}\text { Particle } \\
\text { sedimentati } \\
\text { on time, } \\
\text { min-s }\end{array}$ & $\begin{array}{c}\text { Particle } \\
\text { sedimentati } \\
\text { on rate, } 10^{-} \\
{ }^{5} \mathrm{~m} / \mathrm{s}\end{array}$ & $\begin{array}{c}\text { Particle } \\
\text { sedimentati } \\
\text { on time, h- } \\
\text { min }\end{array}$ & $\begin{array}{c}\text { Particle } \\
\text { sedimentati } \\
\text { on rate, } 10^{-} \\
{ }^{5} \mathrm{~m} / \mathrm{s}\end{array}$ \\
\hline 1 & \multirow{3}{*}{$\begin{array}{c}\text { UST }(v= \\
44 \mathrm{kHz} \\
\tau=15 \\
\min \text { and } \\
\mathrm{t}_{\mathrm{dm}}= \\
\left.40^{\circ} \mathrm{C}\right)\end{array}$} & $10(1)$ & $14-00$ & 18.20 & $52-00$ & 4.90 & $5-10$ & 0.83 \\
\hline 2 & & $30(3)$ & $11-00$ & 23.20 & $26-00$ & 9.81 & $4-50$ & 0.88 \\
\hline 3 & & $50(5)$ & $10-00$ & 25.50 & $22-00$ & 11.59 & $4-20$ & 1.03 \\
\hline 4 & \multirow{3}{*}{$\begin{array}{c}\text { UST }(v= \\
44 \mathrm{kHz} \\
\tau=15 \\
\min \text { and } \\
t_{\mathrm{dm}}= \\
\left.50^{\circ} \mathrm{C}\right)\end{array}$} & $10(1)$ & $11-00$ & 23.20 & $46-00$ & 5.54 & $4-30$ & 0.94 \\
\hline 5 & & $30(3)$ & 9-00 & 28.30 & $21-00$ & 12.14 & $4-10$ & 1.02 \\
\hline 6 & & $50(5)$ & $7-00$ & 36.40 & $17-00$ & 15.00 & $3-50$ & 1.15 \\
\hline
\end{tabular}

It is established that the properties of the material modified by slag suspensions depend on the temperature at which dispersion is carried out. If the dispersing conditions are not observed and the slag suspension is heated, then a rapid coagulation process begins, which results in the aggregation of FGS particles. The mixing of cement with such a suspension results in an uneven distribution of FGS particles in the volume of the material and a deterioration in the strength characteristics of samples with FGS. Thus, to obtain a cement 
stone with increased strength characteristics, it is recommended to control the temperature of the dispersion process of FGS suspensions. The optimal dispersion temperature should vary between $25 \pm 2{ }^{\circ} \mathrm{C}$.

\section{Conclusions}

1. Ultrasonic dispersion of slag suspensions should be carried out at optimal dispersion parameters $v=44 \mathrm{kHz} ; \mathrm{t}=25 \pm 2{ }^{\circ} \mathrm{C} ; \tau=15 \mathrm{~min}$. The application of ultrasonic dispersion to slag suspensions with the observance of dispersing conditions can increase the aggregative and sedimentation stability of FGS suspension by 2-3 times in comparison with the mechanical mixing of suspensions.

2. It is established that in the absence of temperature control of the process of ultrasonic dispersion of FGS suspensions, two competing processes occur: Brownian motion and coagulation of slag particles, which lead to an increase in the sedimentation rate of FGS, a decrease in their aggregative and sedimentation stability, and a decrease in the strength of samples with FGS.

3. Ultrasonic dispersion of slag suspensions helps accelerate the process of micelle formation. Water-dispersed systems using UST behave more stable, the electrostatic factor of aggregative stability is enhanced.

4. Strength characteristics of samples with FGS suspensions prepared using UST under the recommended dispersion conditions are higher than without the use of UST. For the first day of hardening, strength increased by 19 - 39\%; for 28 days of hardening - by $19-36 \%$.

\section{References}

1. A.D. Tolstoj, V.S. Lesovik, L.H. Zagorodnyuk, I.A. Kovaleva, Vestnik MGSU 11, 101-109 (2015)

2. A.A. Volodchenko, V.S. Lesovik, A.N. Volodchenko, E.S. Glagolev, L.H. Zagorodnjuk, Y.V. Pukharenko, International Journal of Pharmacy and Technology 83, 18856-18867 (2016)

3. L.H. Zagorodnyuk, L.D. Shahova, S.V. Yakovlev Beton i zhelezobeton 2, 18-20 (2010)

4. A.R. Hamatova, G.I. Yakovlev, V.P. Grahov, O.V. Hohryakov, Izvestiya Kazanskogo gosudarstvennogo arhitekturno-stroitel'nogo universiteta 4(42), 321-327 (2017)

5. N.A. Shapovalov, L.H. Zagorodnyuk, I.V. Tikunova, A.Yu. Shchekina, A.V. Shkarin, Fundamental'nye issledovaniya 1-1, 167-172 (2013)

6. T.S. Kabanova, Yu.R. Krivoborodov, V.A. Zajcev, Ehnergiya: ehkonomika, tekhnika, ehkologiya 6, 56a-61 (2012)

7. B.V. Gusev, I.L.S. In, Yu.R. Krivoborodov, Tekhnologii betonov 7-8 (72-73), 21-24 (2012)

8. F.L. Kapustin, D.V. Ragozin, A.A. Kuznecov, I.S. Semerikov, A.F. Kapustin, Vestnik YUzhno-Ural'skogo gosudarstvennogo universiteta, Seriya: Stroitel'stvo i arhitektura 15(191), 22-24 (2010)

9. B.Ya. Trofimov, L.Yu. Kramar, K.V. Shuldyakov, Stroitel'nye materialy 9, 96-101 (2013)

10. T.M. Petrova, O.M. Smirnova, S.T. Frolov, Vestnik grazhdanskih inzhenerov 2, 118$123(2011)$ 
11. A. Altun, S. Akpinar, H. Pala, Ogneupory i tekhnicheskaya keramika 11-12, 63-66 (2009)

12. V.S. Lesovik, M.S. Ageeva, A.V. Ivanov, Vestnik Belgorodskogo gosudarstvennogo tekhnologicheskogo universiteta im. V.G. Shuhova 3, 29-32 (2011)

13. P.N. Kil', A.A. Kirsanova, L.Ya. Kramar, B.Yu. Trofimov, I.P. Dobrovol'skij, Vestnik Yuzhno-Ural'skogo gosudarstvennogo universiteta, Seriya: Stroitel'stvo i arhitektura 14-2, 27-32 (2014)

14. L.I. Dvorkin, O.M. Bordyuzhenko, Tekhnologii betonov 5-6, 68 (2010)

15. L.I. Dvorkin, O.L. Dvorkin, Tekhnologii betonov 7(84), 16-18 (2013)

16. N.A. Shapovalov, L.H. Zagorodnyuk, I.V. Tikunova, A.Yu. Shekina, Fundamental'nye issledovaniya 1-2, 439-443 (2013)

17. L.H. Zagorodnyuk, L.D. SHahova, Cement i ego primenenie 1, 172- 175 (2010)

18. S. Samchenko, O. Zemskova, I. Kozlova, MATEC Web of Conferences 106, 03017 (2017) DOI: $10.1051 /$ matecconf/201710603017

19. S.V. Samchenko, O.V. Zemskova, I.V. Kozlova, Russian Journal of Applied Chemistry 87-12, $1872-1876$ (2014) 